\title{
Notes on workshop on kinetics/ESTAC-10, Rotterdam
}

\author{
Sergey Vyazovkin $\cdot$ Crisan Popescu
}

(C) Akadémiai Kiadó, Budapest, Hungary 2011

A workshop on kinetics was a part of the ESTAC-10 conference in Rotterdam. It was organized and moderated by Sergey Vyazovkin, the chairman of the ICTAC committee on kinetics and Crisan Popescu, the chairman of the ICTAC committee on life-time prediction of materials. The workshop was devoted the development of recommendation for kinetic treatment of thermal analysis data. It was attended by numerous participants and was going for $2 \mathrm{~h}$ as an open debate with active involvement of some 20 attendees.

The development of kinetic recommendations was initiated by Sergey Vyazovkin, as chairman of the ICTAC committee on kinetics at ICTAC-14 Congress in Brazil. A draft text of the recommendation was prepared by the following group of authors: Sergey Vyazovkin, Alan K. Burnham, José M. Criado, Luis A. Pérez-Maqueda, Crisan Popescu, and Nicolas Sbirrazzuoli. At the workshop, Sergey Vyazovkin introduced briefly the draft and invited comments from the audience as to what points should be added or stressed more for making the recommendations clearer and more understandable, especially for newcomers to the field of thermal analysis kinetics.

The points raised by the workshop participants can be grouped along the following lines:

\footnotetext{
S. Vyazovkin

Department of Chemistry, University of Alabama at Birmingham, 901 S. 14th Street, Birmingham, AL 35294, USA

C. Popescu $(\square)$

DWI an der RWTH Aachen e.V, Pauwelsstr. 8, 52056 Aachen, Germany

e-mail: popescu@dwi.rwth-aachen.de
}

- the educational need of such recommendations (E. Cavalheiro, J. Malek);

- the degree of generality of various kinetic equations for describing real processes and if the pressure should or not be included in the approach (J. Sestak, M. Pijolat, N. Doca);

- the need to design the experiment to make it specifically suitable for kinetic calculation (M. Pijolat, E. Illekova, M. Bohn, A. Ortega);

- the necessity to produce reliable experimental data and ways to design proper experiments (temperature ranges and heating rates; isothermal and non-isothermal experiments) for acquiring such data (B. Roduit, M. Bohn, A. Ortega, M. Pijolat);

- the importance of correctly estimating the onset of the reaction for autocatalytic reactions (Roduit, Bohn) and of efficiently choosing an appropriate baseline for obtaining suitable data and criteria for judging the suitability (B. Roduit, P. Simon, A. Ortega);

- the correctness and physical meaning of kinetic models, the need for using cross-tests for supporting kinetic calculations, and the importance of kinetics for the purpose of predictions (E. Illekova, J. Malek, D. Ivanov, M. Bohn, P. Simon, J. Sestak, M. Pijolat).

At the end the workshop, the participants were encouraged to request a copy of the draft as well as to submit to Sergey Vyazovkin their specific comments on the draft document by December 1st, 2010. After this date, the authors of the recommendations would revise the draft and prepare the final document. The latter was planned to be published as a paper in Thermochimica Acta to become available by the ICTAC 15 Congress in Japan. 